\title{
Tranexamic acid for trauma-related hemorrhage
}

\author{
Alun Ackery MD MSc, Sandro Rizoli MD PhD
}

\section{Many patients die from bleeding related to trauma}

Uncontrolled hemorrhage causes $30 \%-45 \%$ of all trauma-related deaths. The Clinical Randomisation of an Antifibrinolytic in Significant Haemorrhage (CRASH-2) trial, an international, multicentre randomized controlled trial of tranexamic acid in traumarelated hemorrhage, randomized trauma patients with suspected substantial bleeding (heart rate $>110$ beats $/ \mathrm{min}$, systolic blood pressure $<90 \mathrm{~mm} \mathrm{Hg}$ or both) and those who were considered by their physician to be at substantial risk of bleeding, ${ }^{1}$ to either tranexamic acid or placebo.

Tranexamic acid prevents clot breakdown

Tranexamic acid is an antifibrinolytic agent that binds and inhibits plasmin to stop fibrin breakdown. If hemorrhage is suspected, the recommended dosage is $1 \mathrm{~g}$ intravenously over 10 minutes, followed by $1 \mathrm{~g}$ over eight hours. ${ }^{1}$ Tranexamic acid is inexpensive: it costs about Can $\$ 12$ for $2 \mathrm{~g}$ of treatment, with a cost per life saved of about $\$ 790$.

CMAJ invites submissions to "Five things to know about ..." Submit manuscripts online at http://mc.manuscriptcentral.com/cmaj

\section{There is good evidence that tranexamic acid saves lives}

Results from CRASH-2 showed that trauma patients given tranexamic acid had an improved overall in-hospital mortality at four weeks compared with controls (relative risk $0.91,95 \%$ confidence interval $0.85-0.97$, number needed to treat $=$ 67). ${ }^{1}$ Subgroup analysis suggested that the reduction in mortality was greatest when the agent was given within three hours after injury. Tranexamic acid also appears to confer the greatest benefit to patients with severe injuries and those who receive massive transfusions. ${ }^{1-4}$

\section{Canadian trauma centres are using tranexamic acid}

In Canada, the use of tranexamic acid is standard care in many trauma centres. A currently approved protocol for its use in a Canadian trauma centre is provided in Appendix 1 (www.cmaj.ca/lookup /suppl/doi:10.1503/cmaj.131741/-/DC1). Evidence supporting the use of tranexamic acid in children is lacking, and its use is currently not indicated for isolated head injuries.

\section{References}

1. Shakur H, Roberts I, Bautista R, et al; CRASH-2 Trial collaborators. Effects of tranexamic acid on death, vascular occlusive events, and blood transfusion in trauma patients with significant haemorrhage (CRASH-2): a randomised, placebo-controlled trial Lancet 2010;376:23-32.

2. Roberts I, Shakur H, Afolabi A, et al; CRASH-2 collaborators. The importance of early treatment with tranexamic acid in bleeding trauma patients: an exploratory analysis of the CRASH-2 randomised controlled trial. Lancet 2011;377:1096-101.

3. Roberts I, Shakur H, Ker K, et al; CRASH-2 Trial collaborators. Antifibrinolytic drugs for acute traumatic injury. Cochrane Database Syst Rev 2011;(1): CD004896.

4. Morrison JJ, Dubose JJ, Rasmussen TE, et al. Military Application of Tranexamic Acid in Trauma Emergency Resuscitation (MATTERs) Study. Arch Surg 2012;147:113-9.

5. Keyl C, Uhl R, Beyersdorf F, et al. High-dose tranexamic acid is related to increased risk of generalized seizures after aortic valve replacement Eur J Cardiothorac Surg 2011;39:e114-21.
The potential harms of tranexamic acid in trauma-related hemorrhage appear to be minimal

Despite the theoretical increased risk of coagulation associated with tranexamic acid treatment (e.g., pulmonary embolism, stroke, myocardial infarction), CRASH-2 showed no increased risk of adverse events. ${ }^{1}$ The risk for patients taking anticoagulants is unclear. Intraoperative use of tranexamic acid at high doses ( $>100 \mathrm{mg} / \mathrm{kg}$ ) may increase the risk of seizures. ${ }^{5}$

Competing interests: Sandro Rizoli has received honoraria as a member of the scientific advisory boards for CSL Behring and $\mathrm{KCl}$ Canada. No competing interests were declared by Alun Ackery.

This article has been peer reviewed.

Affiliations: Department of Emergency Medicine (Ackery); Departments of Surgery and Critical Care (Rizoli), St. Michael's Hospital, Toronto, Ont.

Correspondence to: Alun Ackery, alun.ackery @mail.utoronto.ca

CMAJ 2014. DOI:10.1503/cmaj.131741

\section{Resources for clinicians}

Prognosic models are available at the CRASH-2 website

- http://crash2.Ishtm.ac.uk 